\title{
EDITORIAL:
}

\section{Rays of Hope for Planet Earth and Even Its Biosphere*}

\section{INTRODUCTION}

$\mathrm{N}$ ot so many years ago, few if any outside the 'lunatic fringe' of religious fanatics and megalomaniac dictators were apt to refer to our world as in any way seriously threatened, but a decade or two back it became commonplace to do so. For then we were being assailed by a spate of airborne news items, books, and other publications, led perhaps most notably by the late Gordon Rattray Taylor's The Doomsday Book (1970), which seemed to hold out little if any hope for the continuation of our world in anything like the form in which we knew and widely loved it. But now again we can see signs of hope - even some bright rays of light penetrating the dark pall of gloom which, not so very long ago, made many of the enlightened fear, almost to the point of despondency, for the future of our beleaguered Planet Earth.

Meanwhile the general public very widely remained practically oblivious of the dangers threatening the world, despite such attempts at warning as our first International Conference on Environmental Future, in Finland in 1971 (Polunin, 1972), our Second and Third such events in different countries in 1977 (Polunin, 1980) and the summer of 1987 (Polunin \& Burnett, 1990), and other attempts under different auspices rather chronically elsewhere. So later in 1987 I undertook an 'Around the World Talk', lasting about 35 minutes, which I delivered in as many as possible of our points of call. These were London, Quebec City, Montreal, Los Angeles, Seoul, Hong Kong, Singapore, Bahrain, and Geneva. In this talk, entitled 'Our World Menaced', I outlined 20 chosen threats to the world of Mankind and Nature, of which the vast majority were due basically to human overpopulation (Polunin, 1987). Since then - though doubtless advanced far more by other factors than my personal efforts - there has been an enormous surge of public appreciation of the seriousness of those threats, aided no doubt by Time magazine's first issue of 1989, which was entitled 'Planet of the Year: Endangered Earth'. Consequently we feel that a fresh survey is needed, especially of several more helpful or hopeful signs that have emerged of late.

Why has there been this recent change for the better, in the prospect of an improved future for the global environment, at least in the view of some environmental leaders in the latest years? To be sure, something continues to be very wrong - the human response-system is still reacting with lamentable slowness and chronic inadequacy to the uprising challenges of today (Cohen \& Polunin, 1990), and the basic problem of human population and its profligacy is still widely unresolved and indeed growing ever-worse (Shaw, 1989). But there has been, we believe, a distinct improvement of late in general feeling and prospect, and it is the main purpose of this essay to point out how, to attempt some analysis of why, and to include thoughts on what should be done to avoid the abyss which previously seemed unavoidable.

\section{Twelve CHOSEN Hopes}

Not necessarily in their order of importance, but rather of their coming to mind, may be cited the following twleve chosen rays of hope:

1. First I would put the growth and increasing strength of the environmental movement, which all the time guides more and more people, ever-more-widely, to due cognizance and care of their particular environments. Such individual snippets of help mount up to constitute, in The Biosphere as a whole, a very useful surge of support which, increasingly often nowadays, comes to the notice of decision-makers and impresses on governments the need to legislate and insist on concomitant collective action. To this the basic key is education - especially concerning the environment in all its manifold aspects - as we must never forget.

2. Secondly, I would cite the growing realization at last that there are coming to be far too many human beings on our limited Planet Earth, though this all-too-evident fact is still contested by some in a manner which to us seems to constitute the greatest wickedness in the world (if one defines wickedness in terms of global harming). There is no need to recount the demographic facts and figures which have been repeatedly published and publicized; suffice it to say that there are now living some three times as many human beings, probably consuming proportionately more per caput, than when some of us were born and the world was a far less strife-torn habitat. But the realization is dawning widely at last that this cannot go on indefinitely that projections or even predictions of doubling again and yet again are not to be trusted - while the horrors of shortages, famines, overcrowding, and concomitant or other strife, are combining with other facts to lead to population stability in some enlightened countries and actual reduction in some others. Widespread family planning has been valuable in this respect and should help far more with due advocation and spreading of means especially in poor countries. Meanwhile, however, population-pressure of humans together with their domestic animals and pets remains without doubt the greatest basic threat to our world.

* Substance of an invited address to the University Philosophical Society, at Trinity College, Dublin, Ireland, on 16 October 1990. 
3. The recent relaxation of the threat of nuclear warfare, 'nuclear winter', and the hazard of major accidents due to the stockpiling of nuclear weapons and arsenals, is a tremendous relief in view of the recent insane buildup of the capability to destroy - even many times over 'in the twinkling of an eye' - our living world as it has developed through some 3,500 million years. Even though some - probably only primitive - biota might be left alive in secluded places such as deep ocean troughs, this annihilation possibility due to nuclear conflict or accident has latterly been a nightmare of increasing super-severity to those in the know, so that its sudden diminution, with the recent relaxation of tension between the superpowers, constitutes a great advance in our feeling of security and prospects for the future, though the destruction of all thermonuclear weapons in their and other hands still seems a necessity if world security is to be preserved.

4. Regarding the thinning or even destruction of the stratospheric ozone shield, without which life could scarcely have developed, and whose depletion appears already to have led to increased skin-cancer among humans, recent research holds out hopes of improvement in prospect if certain actions are taken concertedly soon. These hopes involved, particularly, Man-made chemicals as indicated in the next, more general, paragraph.

5. Is the realization, borne of improved knowledge with the passage of time, that, if appropriate actions are not taken to counter certain tendencies resulting from activities of Mankind, the result will be grave indeed, and quite likely catastrophic - even globally. An example is the 'attack' on the stratospheric ozone shield by chlorofluorocarbons, which are a purely Man-discovered and Man-made class of chemicals of which the manufacture and use is being phased out following discovery and publicization of the grave dangers inherent in their use. The destruction of arsenals of nuclear weapons might be placed in the same general category.

6. Is the gradual if inevitable turning to 'alternative', and above all indefinitely renewable, sources of energy and power - especially non-polluting ones such as wind, water, and direct solar sources, in the last instance using hydrogen as the vector (Bockris \& Veziroglu, 1985; Bockris, 1990). These should not only suffice for the needs of such humans as the Earth is able to support in other ways, but also avoid continuing pollution and adding further to the worst source of increase of the 'greenhouse effect', namely carbon dioxide.

7. A great help, it seems to me, in getting policymakers and governments to 'make up their minds' to take preventive measures on behalf of the environment, has been mental inculcation and widening realization that the Earth is one, and that anything which affects any part of it may affect the whole. This holistic way of thinking and acting should, I feel strongly, help us in our decisions and concomitant actions as 'Citizens of the World' - and benefit our planetary home ultimately with its spreading.

8. Remedial actions have, very often and extensively in recent decades, taken on one or another form of conservation - of raw capabilities such as forests, of raw materials such as mineral oils, of special areas such as national parks, of disappearing biota in ever-increasing numbers of extinctions, of ecosystems and wider ecocomplexes (Polunin \& Worthington, 1990), and of the specific amenities of our life (as indicated widely in Environmental Conservation, $1974-)$. This is clearly a great improvement over earlier times, when there was little thought and still less action in such respects, and surely represents a marked advance — though not, alas, effectively for tropical forests and their biotas, as was stressed in the Autumn and Winter 1990 issues of Environmental Conservation. A valuable and practicable remedial action is recycling, which is becoming more and more widely practised from the 'grassroots' household level upwards nowadays, and involves more and more materials but so far especially the relatively easily handled categories of paper, glass, and certain metals. Meanwhile, however, much senseless waste continues, such as of precious water in western North America, where it seems that every house has to have its own swimming pool and sometimes two!

9. If, as seems almost inevitable unless AIDS runs its course, we have to put up with, and be part of, an increasingly overcrowded world, it will be necessary to counter human pandominance with the establishment, more and more widely, of artificial ecosystems and ecocomplexes. In suitably-engineered habitats, these can be just as attractive aesthetically and biologically as, and far more productive of biomass and maintained biodiversity than, the natural counterparts which they replace. So perhaps after all we should not be too sad that so many natural features of vegetation and rural life can no longer be preserved in anything like their pristine state, as that with which we can contrive to replace them may be far more attractive and productive than what was there before. This surely constitutes a major advance, at least in prospect. Unfortunately it does not extend to conservation of plant and animal species and other taxa, which continue to disappear from the face of Earth at increasing rates, though it seems conceivable that such extinctions may in time be countered to some extent by genetic manipulation producing new forms to fill ecological gaps with beneficial new dominants.

10. Although they may be accompanied by increased eutrophication (enrichment) due to over-application of fertilizers, or of human disorders due to food or other additives, the increases of recent years in local agricultural productivity, constitute a feat of importance that even human demographers who fear for the 
future of world-wide feeding capability, cannot deny. Such increase is probably helped on one hand by the intensified atmospheric content of carbon dioxide (about $30 \%$ in the last 60 years) increasing photosynthesis, and, on the other, by the higher-than-formerly global temperature, which now appears to be widely agreed upon as having risen about $0.5^{\circ} \mathrm{C}$ in recent years, with probably more to come. It may also be helped by genetic manipulation creating new strains ensuring increased productivity.

11. Quite apart from the nuclear threat dealt with in No. 3, the readiness of the superpowers to change from decades of confrontation to a new area of cooperation, is a major factor and the first mentioned by Dr Gro Harlem Brundtland (pp. xiii-xv in Starke, 1990). Of such readiness the circumstances and auspices are well known, and although it is to be doubted whether environmental considerations loom at all large in the political and military decisions involved, such decisions to collaborate rather than confront should remove a tremendous negative of potential destruction of habitats etc., and at the same time give hopes of huge sums of money being saved for environmental protection and improvement. On the basis that the peace of Mankind should henceforth be more and more with the environment and less and less between armies or other opposing forces, a leading environmental concern and its chief have been nominated for the Nobel Peace Prize, and it is to be hoped that more such recognition of our cause will emerge and become publicly consolidated in the near future.

12. The increasing frequency and general wisdom of declarations concerning the environment, ranging in our case alone from The Reykjavik Imperative on the Environment and Future of Mankind (1977) to the Budapest Imperative on Surviving With The Biosphere (1990) and latterly the Declaration of Biosphere Day (Polunin, 1991 a, 1991b), with many others in between, is surely a good sign. These attempted thrusts may not in themselves amount to much in terms of remedial or ameliorative action; but they do awaken people to the need for such action - thereby constituting some advance - and they do compound to engender realization that people's life-styles and -standards will have to change to meet inevitable shortages and new needs.

\section{Conclusions}

So much for our 'round dozen' of chosen rays of hope for Planet Earth and its threatened environment (particularly The Biosphere). With more and more people crowding the world and vying for depleting resources including living-space, and with the concomitant wide realization that a new order of things for Man and Nature is on its way, we need a successful campaign for the further evolution of Mankind. This latterour unique species - has in many ways come so much farther in its evolution than any other living creature, that it seems inconceivable that it could not find its way or be guided to take one step further to save itself and the world. That all-important and most vital step should be from the present situation in which people think mainly, or often almost exclusively, of their own selfish interests or pursuits, to one in which they think and act first and foremost for the good and future of the world as a whole - see the concluding two paragraphs of Polunin ( $1991 b$, and also page 200 of this issue).

Primary consideration should thus be given to the welfare of The Biosphere - that envelope surrounding our planet which, extending so far down in Earth's depths and up in its attendant atmosphere as any form of life exists naturally, constitutes practically our entire life-support. If only such welfare were the primary and abiding concern of people sufficiently widely in the world, they would surely convert enough of the others to the imperative of saving The Biosphere - so ensuring that the right actions were taken to that paramount end to which all others should surely be subservient. As Strong (1991) puts it in concluding his 'Very Important Prospect' announcing in our columns the United Nations Conference on Environment and Development, to be held next year in Rio de Janeiro, Brazil, 'The protection of The Biosphere as the indispensable basis for the maintenance and well-being of life on Earth must become our highest priority.'.

Further items that remain to be tackled should not be beyond the ingenuity and capability of men and women who conquer human tendencies of selfishness and avarice. They include the 'greenhouse effect', deforestation and other devegetation, desertification, insufficiency of agricultural land, increasing mental instability together with crime and human strife, over-dependence on machines and mechanical devices, major human epidemics such as those of Malaria, garbage and other wastes' disposal, and climatic variation - all of which were already advanced in our 1987 Around the World Talk, and most of which were dealt with, among others, in our 4th International Conference on Environmental Future, entitled Surviving With The Biosphere, of which the book of Proceedings is due for publication very soon by the Edinburgh University Press (Polunin \& Burnett, in press).

We thus see that many of the necessary actions or at least directions which need to be taken to safeguard The Biosphere are now so well known as scarcely to need repetition before a generally enlightened audience. Suffice it to say that, were it not for the indulgence and profligacy of which we are all to some extent guilty, we would not be threatening increasingly the availability of sufficient living-space and other 'raw materials', we would not be threatening the stratospheric ozone shield and overall stability of climate, we would not be 
threatening the seas and limited fresh waters increasingly with pollution, or the soils and forests with salinity and acidity: all could be arranged to save our world.

So let us look to some such advance as the further evolution of Mankind - to a new subspecies or at least forma or other taxon that we may dream of as Homo supersapiens - preferably by persuasive demonstration, failing that by legal processes, or even by genetic manipulation or yet other means, and regardless of how difficult and costly those means might have to be.

\section{NiCHOLAS POLUNIN}

\section{REFERENCES}

BoCKRIS, John O'M. (1990). Is the Solar Hydrogen Energy Scenario the Only Reasonable Alternative to Planetary Warming?, Environmental Conservation, 17(3), pp. 196-7.

BoCKRIS, John O'M. \& VEZIROGLU, T. NEJAT (1985). A Solar-Hydrogen Energy System for Environmental Compatibility. Environmental Conservation, 12(2), pp. 105-18, 2 figs and 6 tables.

BrundtLAND, Gro Harlem (1987). Foreword. Pp. xiii-xv in Signs of Hope: Working Towards our Common Future, by Linda STARKE. Oxford University Press, Oxford, England, UK: xv + 192 pp.

BUdAPEST IMPERATIVE ON SURVIVING With The BiosPhere (1990), Environmental Conservation, 17(2), p. 97.

CoHen, Peter \& Polunin, Nicholas (1990). The Viable Culture. Environmental Conservation, 17(1), pp. 3-6.

ENvironmental ConSERvation (1974-). The Scientific Journal Devoted to Global Survival Published Quarterly by Elsevier Sequoia SA, PO Box 564, 1001 Lausanne 1, Switzerland.

PoLunin, N. (Ed.) (1972). The Environmental Future: Proceedings of the first International Conference on Environmental Future, held in Finland from 27 June to 3 July 1971. Macmillan, London \& Basingstoke, England, UK, and Barnes \& Noble, New York, NY, USA: xiv +660 pp., illustr.

PoLUNIN, N. (Ed.) (1980). Growth Without Ecodisasters? Proceedings of the Second International Conference on Environmental Future (2nd $I C E F$ ). Macmillan, London \& Basingstoke, England, UK, and Halsted Press Division of John Wiley \& Sons, New York, NY, USA: xxvi +675 pp., illustr.

Polunin, Nicholas (1987). Our World Menaced. (Around the World talk of c. 35 minutes, given in London, Quebec City, Montreal, Los Angeles, Seoul, Hongkong, Singapore, Bahrain, and Geneva.). Foundation for Environmental Conservation, Geneva, Switzerland: $7 \mathrm{pp}$. handout (mimeogr.)

PoLunin, Nicholas (1991a). Draft announcement of Biosphere Day. Environmental Conservation, 18(2), p. 118.

Polunin Nicholas (1991b). Declaration of Biosphere Day. Environmental Conservation, 18(3), p. 199.

POLUNIN NichOLAS (1991c). Biosphere Day: A half-dozen prior reactions. Environmental Conservation, 18(3), p. 200.

Polunin, N. \& BurnetT, J.H. (Eds) (1990). Maintenance of The Biosphere: Proceedings of the Third International Conference on Environmental Future (3rd ICEF). [Held in the University of Edinburgh, Scotland, during 24-26 September 1987.] Edinburgh University Press, 22 George Square, Edinburgh EH8 9LF, Scotland, UK. xvi + 228 pp., illustr.

Polunin, N. \& BuRneTt, J.H. (Eds) (in press). Surviving With The Biosphere: Proceedings of the Fourth International Conference on Environmental Future (4th ICEF), held in Budapest, Hungary, 22-27 April 1990. Edinburgh University Press, 22 George Square, Edinburgh EH8 9LF, Scotland, UK.

Polunin, Nicholas \& Worthington, E. Barton (1990). On the Use and Misuse of the Term 'Ecosystem'. Environmental Conservation, 17(3), p. 274.

The Reykjavik Imperative on the Environment and Future of MANKInd (1977), Environmental Conservation, 4(3), pp. 161-3.

SHAW, R. Paul (1989). Rapid population growth and environmental degradation: ultimate versus proximate factors. Environmental Conservation, 16(3), pp. 199-208, 3 figs and table.

Strong, Maurice F. (1991). United Nations Conference on Environment and Development. Environmental Conservation, 18(2), p. 102.

TAYLOR, Gordon Rattray (1970). The Doomsday Book. Thames and Hudson Ltd, London, England, UK: 335 pp. 